\title{
PCNA, Ki-67, p53, bcl-2 and prognosis in intraoral squamous cell carcinoma of the head and neck
}

\author{
Karin Nylander, ${ }^{\mathrm{a}, *}$, Elsy-Britt Schildt ${ }^{\mathrm{b}}$, Mikael Eriksson ${ }^{\mathrm{b}}$ and Göran Roos ${ }^{\mathrm{a}}$ \\ Departments of ${ }^{\mathrm{a} P a t h o l o g y}$ and ${ }^{\mathrm{b}}$ Oncology, Umeå University, S-901 87 Umeå, Sweden
}

Received 16 January 1997

Revised 3 April 1997

\begin{abstract}
Eighty patients with primary intraoral squamous cell carcinomas of the head and neck, with a follow-up of 4-14 years were analysed for clinical outcome in relation to immunohistochemical expression of PCNA, Ki-67, p53, bcl-2 and presence of mutations in the p53 gene. The tumour site was not associated with the different parameters calculated. PCNA and Ki-67 labelling showed median values of 56\% and 32\%, respectively, and neither antigen was of predictive value. Fiftyfive percent of the tumours expressed p53, and 38 (48\%) had mutations in the p53 gene. No association between the presence of p53 protein or mutations in the p53 gene and clinical outcome was found. Bcl-2 positivity was detected in a minor fraction $(10 \%)$ of the tumours.
\end{abstract}

Keywords: Immunohistochemistry, mutation analysis, prognosis, head and neck, squamous cell carcinoma

\section{Introduction}

In the diagnostic characterisation of tumours a major problem is to define parameters of clinical significance regarding therapy response and prognosis, which would provide the means for more individually based treatment. For squamous cell carcinoma of the head and neck (SCCHN) the prognostic significance of various parameters has been thoroughly studied, indicating the presence of regional metastasis as a main prognostic factor $[10,23,43]$. Tumour cell kinetic properties have raised much interest, and for some tumours the cell proliferation rate has been shown to be of predictive value [31]. The prognostic impact of cell proliferation can, however, vary within a specific group of tumours due, for example, to differences in tumour grade [31].

A frequently used method to study cell proliferation is immunohistochemical detection of cell cycle related antigens such as Ki-67 and PCNA (proliferating cell nuclear antigen). The Ki-67 antigen, which is present in the G1, S, G2 and M-phases of the cell cycle but absent in G0 cells [12,13], can provide information on the fraction of actively cycling cells [4]. In certain malignant tumours the number of tumour cells positive for Ki-67 coincided with the estimated tumour proliferation rates [11].

\footnotetext{
${ }^{*}$ Corresponding author. Address: Department of Pathology, Umeå University, S-90187 Umeå, Sweden. Tel.: + 4690785 1591; fax: + 46907852829 .
} 
In a recent study Ki-67 expression was of no predictive value in a group of SCCHN, consisting of a mixture of oral, laryngeal and pharyngeal tumours, as well as neck dissection specimens [33].

In normal tissues and lymphoid neoplasms expression of PCNA can be used as a cell kinetic marker, whereas the relation between PCNA expression and cell proliferation in some neoplasias can be lost [18]. The use of PCNA as a proliferation marker can thus be questioned, since growth factors have been shown to cause overexpression of PCNA in some tumours without a concomitant cell proliferation [24]. Several tumour types have been studied concerning PCNA expression and prognosis, giving different results $[1,9,17,38,41]$. In mucoepidermoid carcinoma and breast carcinoma expression of PCNA was indicated to be an important parameter in predicting survival $[1,9,17,38]$, whereas no correlation to prognosis could be seen in malignant melanoma and a group of mainly laryngeal and pharyngeal SCCHN $[20,41]$.

Mutations in the p53 tumour suppressor gene are the most common genetic alteration found in SCCHN [37], and overexpression of the p53 protein has been demonstrated in 34-80\% of the tumours studied $[5,8,15,22,29,40]$. The normal p53 product functions as "guardian of the genome" with the ability to stop cells with DNA-damage in late G1 phase [21]. Significantly higher cell proliferation, as judged by Ki-67 expression, has been seen in well differentiated p53 immunopositive oral carcinoma [40], but no prognostic information was given by p53 overexpression [19]. In our previous studies of SCCHN no relationship between either p53 expression or p53 mutation and cell proliferation judged by in vivo incorporation of IdUrd was found [28,29], and no correlation between immunohistochemically detectable p53 protein and mutation in the p53 gene was present [29]. A mutation in the p53 gene leads to an increase in protein half life facilitating immunohistochemical detection. But an increase in half life can also be achieved by binding of wild type p53 protein to other proteins or by disturbance in the degradation pathway [42].

Expression of PCNA and p53 has shown in esophageal carcinoma and astrocytic neoplasms a strong correlation [16,35], whereas no such correlation was found in SCCHN [28]. By inducing the Cip1 protein, p21, wild type p53 protein can indirectly and selectively inhibit PCNA activity in DNA replication, whereas the PCNA function in nucleotide excision-repair is unaffected [36]. Wild type p53 protein can also induce apoptosis, a process that can be blocked by the bcl-2 protein by diversion of p53 activity from induction of apoptosis to induction of growth arrest [6]. In an immunohistochemical study of so-called stem cell SCCHN bcl-2 was found in $40 \%$ of the tumours accompanied by strong proliferation [3]. No data concerning bcl-2 expression and prognosis in SCCHN are so far available.

The aim of the present work was to evaluate the possible prognostic significance of a number of cell proliferation and apoptosis associated parameters in a large number of retrospective material consisting only of primary intraoral SCCHN with long clinical follow-up. None of the parameters studied, i.e., Ki-67, PCNA, p53 and bcl-2 was found to have any obvious impact on prognosis for this patient group. Nor did the values calculated for the parameters differ with respect to tumour site.

\section{Material and methods}

\subsection{Material}

Formalin fixed and paraffin embedded samples from 80 tumours with a follow-up between 4-14 years were included in the study. Thirtysix tumours were located in gingival/buccal mucosa, 18 in tongue, 16 in the floor of the mouth, six in tonsil/mesopharynx and the remaining four in epipharynx. Forty-three (54\%) of the patients were women and 37 men, with an overall mean age of 66 years (range 32-91). 


\subsection{Antibodies and staining}

Five- $\mu \mathrm{m}$ sections were cut from each block, and left at room temperature overnight. For detection of PCNA, Ki-67, p53 and bcl-2, respectively, the following antibodies were used: PC10, a mouse monoclonal antibody (Novocastra Laboratories Ltd., Newcastle, UK), recognising an epitope within aa 111-125 of the PCNA protein [34]; MIB-1, a monoclonal antibody against Ki-67 (BioGenex, San Ramon, CA, USA) [25]; DO7 a monoclonal antibody (Novocastra) recognising a denaturation resistant epitope between amino acids 1 and 45 in wild type as well as mutant p53 protein [39]; and M0887, a monoclonal antibody (Dakopatts A/S, Denmark) against bcl-2. The PCNA and p53 antibodies were diluted $1: 50$, the Ki-67 antibody $1: 25$ and the bcl-2 antibody $1: 70$. As secondary antibody for PCNA, p53 and bcl-2 an alkaline phosphatase conjugated rabbit anti-mouse antibody (D 314; Dakopatts) was used, and for detection of the Ki-67 antibody a super sensitive Multi Link Kit (BioGenex) was applied. For visualisation of the staining reactions fast red (Sigma Chemical Co, St Louis, MO, USA) was used.

Preincubation of slides in methanol was performed before staining with the PC10 antibody, and when staining with the Ki-67 and bcl-2 antibodies slides were pretreated in $10 \mathrm{mM}$ citrate-buffer using a microwave oven at full effect $(900 \mathrm{~W})$ for $2.5 \mathrm{~min}$ and at $350 \mathrm{~W}$ for $9 \mathrm{~min}$. Slides were left to cool for 20-30 min and then rinsed in distilled water. Incubation with the primary antibodies was carried out at $4{ }^{\circ} \mathrm{C}$ overnight. After rinsing in TRIS buffer, slides were incubated with the secondary antibody at room temperature for $45 \mathrm{~min}$, and with the Multi Link Kit according to the supplier's recommendation.

\subsection{Immunohistochemical evaluation}

For PCNA and Ki-67 stained slides a labelling index (LI) was calculated as earlier described in detail [27]. In brief, a $10 \times 10$ square grid comprising 121 cross points was fitted into the eyepiece of the microscope using an objective lens of $\times 40$, and cells showing a distinct nuclear staining were counted in 5-10 randomly chosen fields, in most cases covering the whole tumour. The average LI was calculated as the percentage of positively stained nuclei falling in the crossing between two lines of the grid. The immunohistochemical evaluation and calculation of LI was performed by one of the authors $(\mathrm{KN})$. Control calculations of LI showed an intra-observer variation that was not statistically significant.

For p53 and bcl-2, tumours were graded positive or negative, where tumours with only occasional p53 positive cells were considered negative. For bcl-2 the group of positive tumours was so small, that a proper evaluation of different LIs was not considered relevant.

\subsection{PCR and SSCP (single strand conformation polymorphism) analysis}

DNA was extracted from the paraffin blocks, and PCR/SSCP analysis of exons 5-9 of the p53 gene was performed the same way as earlier described in detail [29]. All mutations found in exon 8 were further sequenced. This was due to the unexpected dominance of mutations in exon 8 as well as the concordance in aberrant gel pattern in many of these tumours.

\subsection{Statistical analysis}

For analysis of crude survival, curves were constructed using the method of Kaplan and Meier, with statistical significance determined by the Chi square test. For PCNA and Ki-67 expression tumours 
were divided into three almost equal groups referring to LI, and for p53 expression two groups were analysed; p53 positive and p53 negative tumours, respectively. The bcl-2 positive group of tumours was too small (only 8 cases) to allow any meaningful survival analysis. For comparison of calculated values between different tumour sites the Kruskal Wallis and log-rank test were used.

\section{Results}

\subsection{Immunohistochemical evaluation}

Seventy-six of the 80 tumours showed a positive staining for PCNA. In the remaining four tumours the staining reaction did not work. PCNA positive cells were found in the basal and parabasal layers of the tumours, no staining was seen in keratinised areas. PCNA expressing cells could also be found in the basal and parabasal layers of normal adjacent epithelium. PCNA staining was clearly nuclear and, although a slight difference in staining intensity was seen in most tumours, cells showing nuclear staining were recorded positive irrespective of intensity. In some areas of the epithelium a weak to distinct reactivity in the cytoplasm could also be seen. This cytoplasmic staining was most probably unspecific, and did not affect calculation of LI since only cells with nuclear staining were included in the calculation. LI for PCNA showed a median value of 56\% (range 14-93\%, Table 1).

Material from 77 tumours could successfully be analysed for expression of the Ki-67 antigen, and positive cells were located in the same areas as PCNA positive cells, but the Ki-67 expressing cells were mainly restricted to the most basal layers. The number of Ki-67 positive cells was therefore in most tumours lower than the amount of cells expressing PCNA, with a median value for LI of $32 \%$ (range 11-60\%, Table 1). No significant correlation was found between Ki-67 and PCNA labelling indices.

Forty-four of the 80 tumours $(55 \%)$ expressed the p53 protein. Only cells with a clear nuclear staining were considered positive. Staining intensity did not markedly differ between tumours. Cells positive for p53 were located in the same areas as PCNA and Ki-67 expressing cells, but were only occasionally detected in normal adjacent epithelium. Forty-five mutations in the p53 gene were found distributed in 38 of the tumours since seven tumours had two mutations. At sequencing, 17 of the mutations were represented by a novel non random deletion in exon 8 [30]. SSCP detected mutations

Table 1

Summary of immunohistochemical data regarding Ki-67, PCNA, p53 and bcl-2 and SSCP data on p53 gene alterations

\begin{tabular}{|c|c|c|c|c|c|c|}
\hline & \multirow{2}{*}{$\begin{array}{l}\text { Median } \\
\text { LI/Ki-67* }\end{array}$} & \multirow{2}{*}{$\begin{array}{c}\text { Median } \\
\text { LI/PCNA* }\end{array}$} & \multicolumn{2}{|c|}{ p53* } & \multirow{2}{*}{$\begin{array}{l}\text { bcl-2 } \\
\text { pos. }\end{array}$} & \multirow[t]{2}{*}{ No } \\
\hline & & & $\mathrm{IHC}+$ & $\mathrm{SSCP}+$ & & \\
\hline All & 32 & 56 & 55 & 48 & 10 & 80 \\
\hline LI/Ki-67 > median & - & 60 & 50 & 45 & 3 & 38 \\
\hline $\mathrm{LI} / \mathrm{Ki}-67 \leqslant$ median & - & 52 & 59 & 46 & 18 & 39 \\
\hline LI/PCNA > median & 36 & - & 55 & 55 & 8 & 38 \\
\hline $\mathrm{LI} / \mathrm{PCNA} \leqslant$ median & 30 & - & 58 & 42 & 11 & 38 \\
\hline p53, SSCP+ & 32 & 59 & 50 & - & 8 & 38 \\
\hline p53, SSCP- & 32 & 54 & 60 & - & 12 & 42 \\
\hline $\mathrm{p} 53, \mathrm{IHC}+$ & 30 & 56 & - & 43 & 9 & 44 \\
\hline p53, IHC- & 33 & 57 & - & 53 & 11 & 36 \\
\hline
\end{tabular}

${ }^{*}$ Given as $\%$. 
were found in a similar frequency in p53 positive and negative tumours, in agreement with our previous study [29] (Table 1). Thus, no association between p53 overexpression and p53 gene mutations could to demonstrated.

Sections from 78 tumours were stained for bcl-2 protein, and eight of these tumours showed a distinct cytoplasmic staining (Table 1). The staining pattern was heterogeneous within the tumours, i.e., in some areas only basal cells were stained, whereas in other areas staining in all cell layers was seen.

\subsection{Subgrouping of tumours with respect to localisation}

The complete group of 80 tumours was subdivided into five groups depending on localisation, and a comparison of calculated values was made. No statistically significant difference was seen for PCNA, Ki-67, p53 protein or p53 mutations between the different locations. Concerning bcl-2 expression, a difference between various sites could be seen. The group of bcl-2 positive tumours, however, consisted only of eight tumours, and the data must therefore be interpreted with care (Table 2).

\subsection{Correlation to prognosis}

PCNA or Ki-67 expression was not associated with crude survival (Figs 1 and 2). Also, no significant difference was found in crude survival for patients with p53 positive or negative tumours, although a tendency towards a worse prognosis could be seen for patients with 53 positive tumours $(p=0.143$, Fig. 3).

LIs for PCNA or Ki-67 were similar for p53 positive and negative tumours, and gave no predictive information within the p53 subgroups.

\subsection{Mutation analysis}

Regarding p53 gene mutations, no association was seen between the presence of mutations and clinical outcome (Fig. 4). As mentioned above, a significant fraction of the mutated tumours showed the same deletion in exon 8 , but even if these cases were excluded no prognostic information was given by the p53 mutational status. Furthermore, the presence of a p53 mutation seemed to be of no relevance for tumour cell proliferation as judged by Ki-67 or PCNA expression.

Although the group of bcl-2 positive tumours was very small, it can be noted that all except one of the bcl-2 positive cases had a Ki-67 LI below median.

Table 2

Median values for the different parameters with respect to localisation

\begin{tabular}{lcccccc}
\hline Localisation & $\mathrm{p} 53 / \mathrm{IHC}+$ & $\mathrm{p} 53$ mut+ & PCNA & Ki-67 & bcl-2+ & No \\
& $\%$ & $\%$ & $\%$ & $\%$ & $\%$ & \\
\hline All & 55 & 48 & 56 & 32 & 10 & 80 \\
Gingiva/bucca & 53 & 47 & 55 & 30 & 6 & 36 \\
Tongue & 56 & 56 & 63 & 36 & 6 & 18 \\
Floor of mouth & 44 & 62 & 58 & 36 & 6 & 16 \\
Tonsil/mesopharynx & 83 & 17 & 50 & 28 & 40 & 6 \\
Epipharynx & 75 & 100 & 52 & 28 & 50 & 4 \\
\hline
\end{tabular}




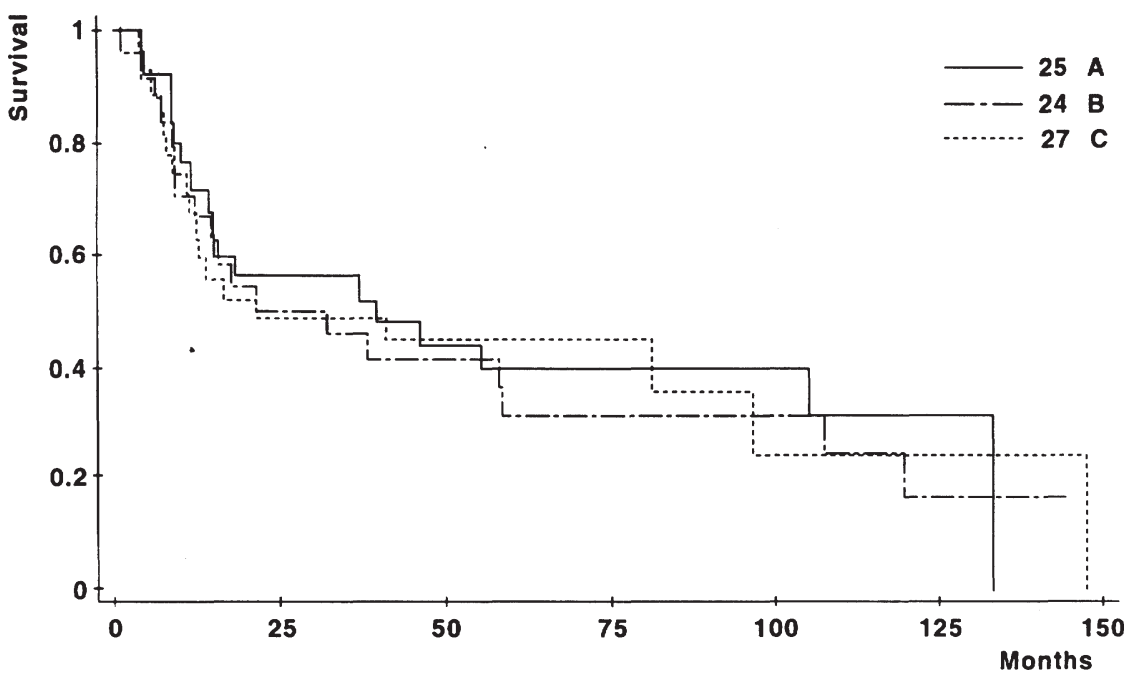

Fig. 1. Crude survival for PCNA expression. Patients were divided into three groups according to LI; group A: LI 14-47\%, group B: LI $48-65 \%$ and group C: LI 66-93\%. No statistically significant difference in crude survival was found between the groups.

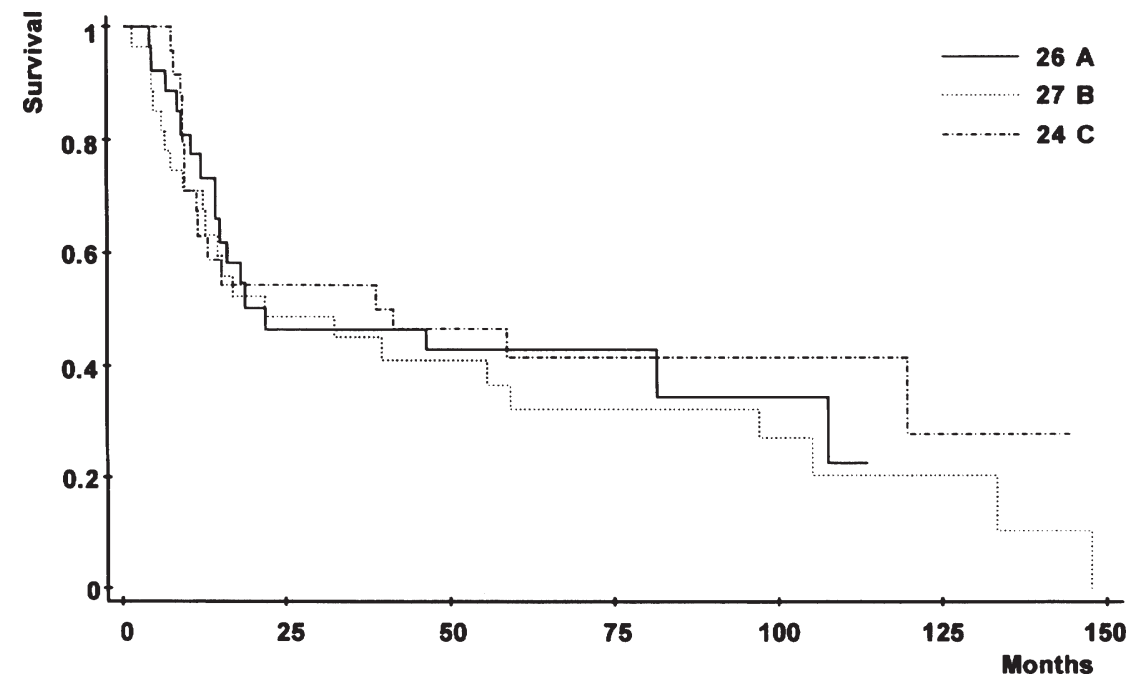

Fig. 2. Crude survival for Ki-67 expression. Patients were divided into three groups; group A: LI 11-24\%, group B: LI 25-38\% and group C: LI 39-60\%. No significant difference in crude survival was found between the three groups.

\section{Discussion}

In the present study the prognostic significance of a number of proliferation and apoptosis associated proteins were studied in a group consisting only of intraoral SCCHN. Neither PCNA nor Ki-67 expression seemed to have any impact on the prognosis which is in agreement with previous reports using immunohistochemistry on the whole group of SCCHN [20,33]. No relationship between these two cell cycle related proteins was observed in contrast to an earlier study by Jones et al. [20] who did find a strong correlation. In Jones' study, however, only four of 37 SCCHN were oral carcinomas, and accordingly their results were achieved mainly from laryngeal and pharyngeal tumours and are 


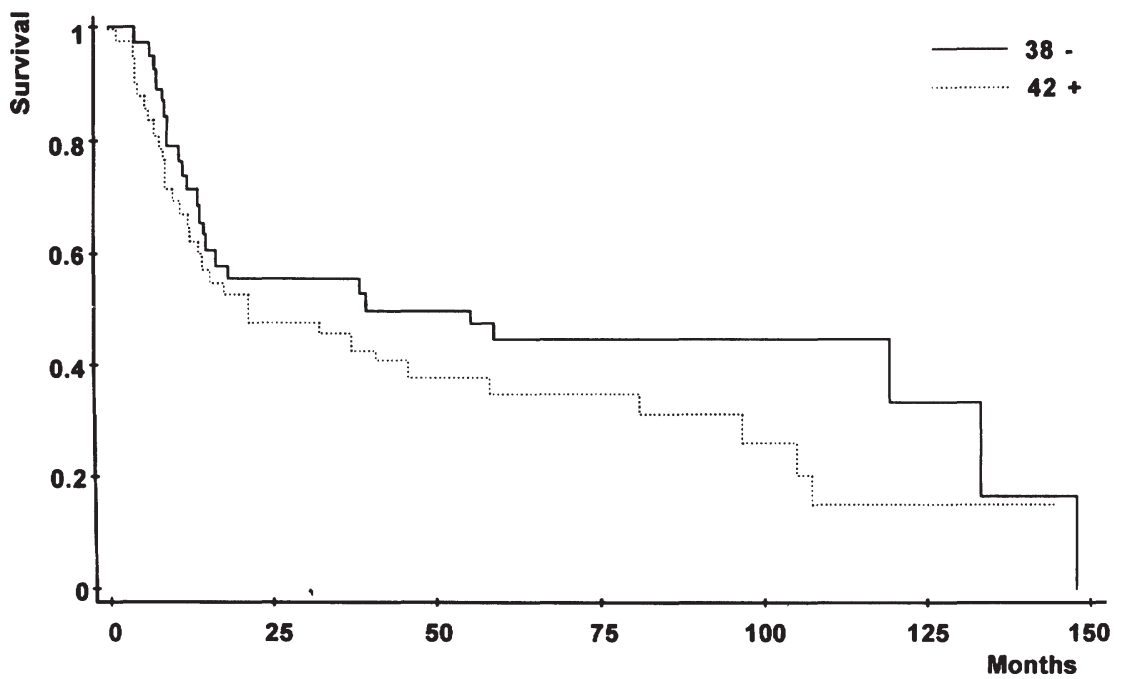

Fig. 3. Crude survival for $\mathrm{p} 53$ expression. Patients were divided into two groups: one with p53 positive and the other with p53 negative tumours. No significant difference was found between the groups, though a tendency for worse survival could be seen for patients with $\mathrm{p} 53$ positive tumours.

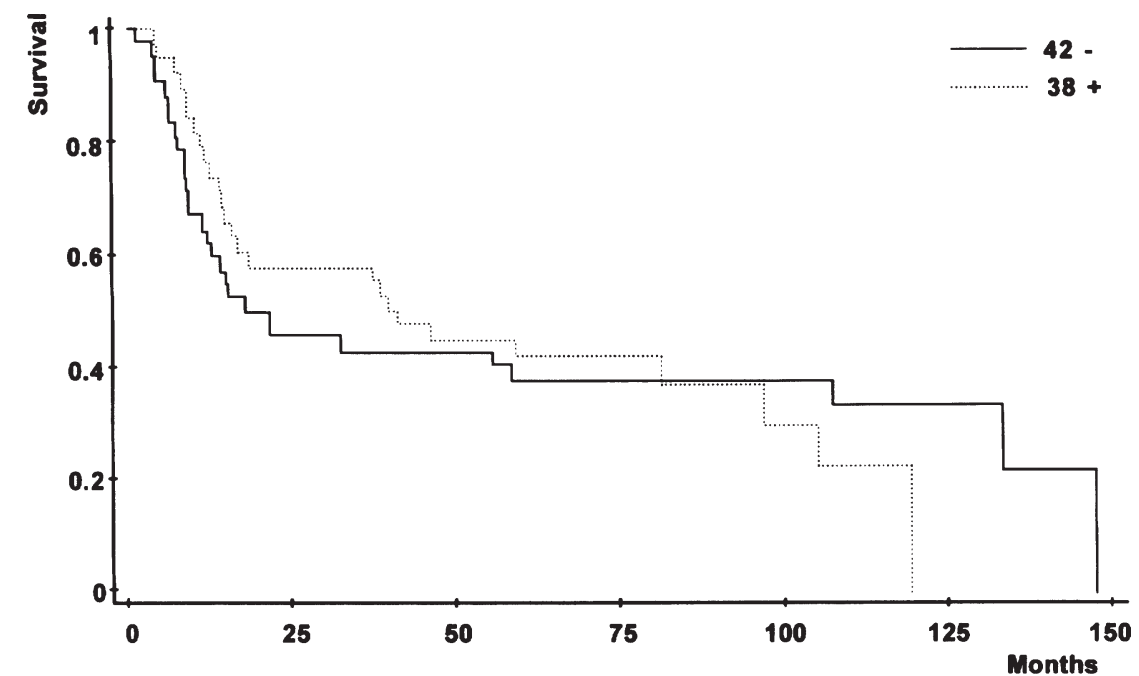

Fig. 4. Crude survival for p53 mutations, including the 17 tumours with the new non random deletion. No difference in crude survival was seen between tumours with and without mutation.

not comparable to our data from oral carcinomas only. In our hands the expression of at least one of the two parameters, Ki-67 and PCNA, was unrelated to tumour cell growth. In many tumours PCNA positive cells were found in parabasal layers with more differentiated cells, which can be explained by the long half life of PCNA making it detectable also in cells that had left the cell cycle. In contrast, Ki-67 expression was restricted to the most basal and proliferative compartment of the epithelium similar to findings in benign tissues. Regarding PCNA, the possibility of a growth factor induced and cell cycle unrelated expression must also be taken into consideration [18,24]. In summary, these data indicate that PCNA can be questioned as a reliable marker of cell proliferation in intraoral SCCHN. It can not be stated from the present study that Ki-67 is a useful cell growth marker either. 
By using PCNA/Ki-67 immunohistochemistry it is not possible to make a definite distinction between actively proliferating cells and cells arrested in the cell cycle. Therefore, if cell cycle arrest or transit out of active cell cycle are common events in SCCHN usual PCNA and Ki-67 stainings might give a false representation of the growth fraction. Consequently, in studies of cell cycle related antigens arrested cells must be considered as a confounding factor. A double labelling approach using, e.g., Ki-67 and a marker for resting cells such as statin [2] could perhaps solve this problem by distinguishing arrested cells from proliferating cells. Dynamic cell kinetic measurements can be made after in vivo labelling with thymidine analogues, like iodo- and bromodeoxyuridine, and estimation of the potential tumour doubling time $\left(T_{\mathrm{pot}}\right)$ can be made. $T_{\text {pot }}$ estimations can give useful clinical information and in a previous study using iododeoxyuridine labelling we found that prognostic information might be achieved by analysis of dynamic cell kinetic parameters [27].

The p53 protein exerts a check point control in late G1 phase, preventing replication of cells with DNA damage [21], and a mutation in the gene will likely result in a defective G1 control. In tumours with p53 gene mutations a higher proliferation rate could be expected in comparison with wild type p53 tumours. In the present study no association between the presence of a p53 mutation and the expression of proliferation associated antigens was demonstrated. One explanation for this could be that the mutation was present in only a minor fraction of the tumour cells giving no measurable effect on cell kinetic parameters. It must also be remembered that there are other regulators of cell cycle progression effective in the G1 phase, like the Rb-protein and cyclins D and E [14,32]. The p53 induced cyclin dependent kinase inhibitor p21 interacts with a number of proteins including cdks, cyclin D1 and PCNA leading to cell cycle arrest $[7,32,36]$. However, p21 can also be induced in a p53 independent pathway [26]. No relationship between p53 protein expression and presence of mutations was found, which can be explained by a large fraction of nonsense mutations and the fact that the antibody used detected wild type as well as mutated p53 protein [27,29]. Our data indicated that regarding intraoral SCCHN the p53 status is of limited importance for regulation of cell kinetic events as well as for prognosis.

The data from the present study of intraoral SCCHN seemed to rule out a prognostic significance of some frequently used cell proliferation and apoptosis associated parameters. Expression of the bcl-2 protein in SCCHN has previously only been reported once, showing a much higher percentage of bcl-2 positive tumours in a subgroup of SCCHN than in our study [3]. The bcl-2 positive tumours studied by Bosch et al. were judged as stem cell tumours with a high proliferation rate, whereas all our bcl-2 positive tumours were regular squamous cell carcinomas.

The group of intraoral SCCHN comprises tumours from different locations, such as tongue, floor of mouth, gingiva/buccal mucosa and tonsil. We could, however, show that the expression of PCNA, $\mathrm{Ki}-67, \mathrm{p} 53$ protein and presence of p53 mutations were independent of tumour site.

\section{Acknowledgements}

The authors wish to thank Ms Britta Lindgren for excellent technical assistance. This study was supported by grants from the Swedish Cancer Society, Lion's Research Foundation, Umeå University, the Swedish Dental Society and the Västerbotten County Council.

\section{References}

[1] S. Aaltomaa, P. Lipponen and K. Syrjänen, Prognostic value of cell proliferation in breast cancer as determined by proliferating cell nuclear antigen (PCNA) immunostaining, Anticancer Res. 12 (1992), 1281-1286. 
[2] B. Ansari, R. Dover, C.P. Gillmore and P.A. Hall, Expression of the nuclear membrane protein statin in cycling cells, J. Pathol. 169 (1993), 391-396.

[3] F.X. Bosch and T. Andl, Expression of bcl-2 in a subclass of squamous cell carcinomas of the head and neck: are they stem cell tumours?, Proceedings of the American Association for Cancer Research 36, Baltimore, 26 March 1995.

[4] D.C. Brown and K.C. Gatter, Monoclonal antibody Ki-67: its use in histopathology, Histopathol. 17 (1990), $489-503$.

[5] J. Caamano, S.Y. Zhang, E.A. Rosvald, B. Bares and A.J.P. Klein-Szanto, p53 alterations in human squamous cell carcinomas and carcinoma cell lines, Am. J. Pathol. 142 (1993), 1131-1139.

[6] S.K. Chiou, L. Rao and E. White, bcl-2 blocks p53-dependent apoptosis, Mol. Cell Biol. 14 (1994), $2556-2563$.

[7] W.S. El-Deiry, T. Tokino, V.E. Velculescu, D.B. Levy, R. Parsons, J.M. Trent, D. Lin, W.E. Mercer, K.W. Kinzler and B. Vogelstein, WAF1, a potential mediator of p53 tumour suppression, Cell 75 (1993), 817-825.

[8] J.K. Field, D.A. Spandidos, A. Malliri, J.R. Gosney, M. Yiagnisis and P.M. Stell, Elevated p53 expression correlates with a history of heavy smoking in squamous cell carcinoma of the head and neck, Br. J. Cancer 64 (1991), 573-577.

[9] R.A. Frankenthaler, A.K. El-Naggar, N.G. Ordonez, T.S. Miller and J.G. Batsakis, High correlation with survival of proliferating cell nuclear antigen expression in mucoepidermoid carcinoma of the parotid gland, Otolaryngol. Head Neck Surg. 111 (1994), 460-466.

[10] G. Franzén, Prognostic and therapeutic indications of DNA content in squamous cell carcinomas of the upper respiratory-digestive tract. MedSci. Thesis, University of Bergen, Norway, and Linköping, Sweden, 1989.

[11] J. Gerdes, U. Schwab, H. Lemke and H. Stein, Production of a mouse monoclonal anti-body reactive with a human nuclear antigen associated with cell proliferation, Int. J. Cancer 31 (1983), 13-20.

[12] J. Gerdes, H. Lemke, H. Baisch, H.H. Wacker, U. Schwab and H. Stein, Cell cycle analysis of a cell proliferationassociated human nuclear antigen defined by the monoclonal antibody Ki-67, J. Immunol. 133 (1984), 1710-1715.

[13] J. Gerdes, L. Li, C. Schlueter, M. Duchro, C. Wohlenberg, C. Gerlach, I. Stahmer, S. Kloth, E. Brandt and H.D. Flad, Immunobiochemical and molecular biologic characterization of the cell proliferation-associated nuclear antigen that is defined by monoclonal antibody Ki-67, Am. J. Pathol. 138 (1991), 867-873.

[14] X. Graña and E. Premkumar Reddy, Cell cycle control in mammalian cells: role of cyclins, cyclin dependent kinases (CDKs), growth suppressor genes and cyclin-dependent kinase inhibitors (CKIs), Oncogene 11 (1995), 211-219.

[15] B. Gusterson, R. Anbazhagan, W. Warren, C. Midgely, D.P. Lane, M. O'Hare, A. Stamps, R. Carter and H. Jayatilake, Expression of p53 in premalignant and malignant squamous epithelium, Oncogene 6 (1991), 1785-1789.

[16] H. Haapasalo, J. Isola, P. Sallinen, H. Kalimo, H. Helin and I. Rantala, Aberrant p53 expression in astrocytic neoplasms of the brain: association with proliferation, Am. J. Pathol. 142 (1993), 1347-1351.

[17] T. Haerslev and G. Krag Jacobsen, Proliferating cell nuclear antigen in breast carcinomas. An Immunohistochemical study with correlation to histopathological features and prognostic factors, Virchows Archiv 424 (1994), 39-46.

[18] P.A. Hall, D.A. Levison, A.L. Woods, C.C. Yu, D.B. Kellock, J.A. Watkins, D.M. Barnes, C.E. Gillett, R. Camplejohn and R. Dover, Proliferating cell nuclear antigen (PCNA) immunolocalization in paraffin sections: an index of cell proliferation with evidence of deregulated expression in some neoplasms, J. Pathol. 162 (1990), 285-294.

[19] A. Högmo, E. Munck-Wikland, R. Kuylenstierna, J. Lindholm and G. Auer, Nuclear DNA content and p53 immunostaining in oral squamous cell carcinoma - an analysis of a consecutive 10-year material, Int. J. Oncol. 5 (1994), 915-920.

[20] A.S. Jones, N.J. Roland, A.W. Caslin, T.G. Cooke, L.D. Cooke and G. Forster, A comparison of cellular proliferation markers in squamous cell carcinoma of the head and neck, J. Laryngol. Otology 108 (1994), 859-864.

[21] D.P. Lane, p53, guardian of the genome, Nature 358 (1992), 15-16.

[22] J.D. Langdon and M. Partridge, Expression of the tumour suppressor gene p53 in oral cancer, Br. J. Oral Maxillofac. Surg. 30 (1992), 214-220.

[23] G. Mamelle, J. Pampurik, B. Luboinski, R. Lancar, A. Lusinchi and J. Bosq, Lymph node prognostic factors in head and neck squamous cell carcinomas, Am. J. Surg. 168 (1994), 494-498.

[24] D. McCormick and P.A. Hall, The complexities of proliferating cell nuclear antigen, Histopathol. 21 (1992), $591-594$.

[25] D. McCormick, H. Chong, C. Hobbs, C. Datta and P.A. Hall, Detection of the Ki-67 antigen in fixed and wax-embedded sections with the monoclonal antibody MIB1, Histopathol. 22 (1993), 355-360.

[26] P. Micheli, M. Chedid, D. Lin, J.H. Pierce, W.E. Mercer and D. Givol, Induction of WAF1/CIP1 by a p53-independent pathway, Cancer Res. 54 (1994), 3391-3395.

[27] K. Nylander, G. Anneroth, H. Gustafsson, G. Roos, R. Stenling and B. Zackrisson, Cell kinetics of head and neck squamous cell carcinomas. Prognostic Implications, Acta Oncol. 33 (1994), 23-28.

[28] K. Nylander, R. Stenling, H. Gustafsson, B. Zackrisson and G. Roos, p53 expression and cell proliferation in squamous cell carcinomas of the head and neck, Cancer 75 (1995), 87- 93.

[29] K. Nylander, P. Nilsson, C. Mehle and G. Roos, p53 mutations, protein expression and cell proliferation in squamous cell carcinomas of the head and neck, Br. J. Cancer 71 (1995), 826-830.

[30] K. Nylander, E.B. Schildt, M. Eriksson, A. Magnusson, C. Mehle and G. Roos, A nonrandom deletion in the p53 gene in oral squamous cell carcinoma, Br. J. Cancer 73 (1996), 1381-1386. 
[31] S.M. O'Reilly and M.A. Richards, Clinical aspects of assessing cell proliferation, in: Assessment of Cell Proliferation in Clinical Practice, P.A. Hall, D.A. Levison and N.A. Wright, eds, Springer, London, Berlin, Heidelberg, New York, Paris, Tokyo, Hong Kong, Barcelona, Budapest, 1992, pp. 177-191.

[32] J. Pines, Cyclins, CDKs and cancer, Cancer Biol. 6 (1995), 63-72.

[33] N.J. Roland, A.W. Caslin, G.L. Bowie and A.S. Jones, Has the cellular proliferation marker Ki-67 any clinical relevance in squamous cell carcinoma of the head and neck?, Clin. Otolaryngol. 19 (1994), 13-18.

[34] G. Roos, G. Landberg, J.P. Huff, R. Houghten, Y. Takasaki and E.M. Tan, Analysis of the epitopes of proliferating cell nuclear antigen recognized by monoclonal antibodies, Lab. Invest. 68 (1993), 204-210.

[35] H. Sasano, S. Miyazaki, Y. Gooukon, T. Nishihira, T. Sawai and H. Nagura, Expression of p53 in human esophageal carcinoma: An immunohistochemical study with correlation to proliferating cell nuclear antigen expression, Hum. Pathol. 23 (1992), 1238-1243.

[36] M.K.K. Shivji, S.J. Grey, U.P. Strausfeld, R.D. Wood and J.J. Blow, Cip1 inhibits DNA replication but not PCNAdependent nucleotide excision-repair, Current Biology 4 (1994), 1062-1068.

[37] K.D. Somers, A. Merrick, M.E. Lopez, L.S. Incognito, G.L. Schechter and G. Casey, Frequent p53 mutations in head and neck cancer, Cancer Res. 52 (1992), 5997-6000.

[38] S.R. Tahan, D.S. Neuberg, A. Dieffenbach and L. Yacoub, Prediction of early relapse and shortened survival in patients with breast cancer by proliferating cell nuclear antigen score, Cancer 71 (1993), 3552-3559.

[39] B. Vojtesek, J. Bartek, C.A. Midgley and D.P. Lane, An immunochemical analysis of the human nuclear phosphoprotein p53. New monoclonal antibodies and epitope mapping using recombinant p53, J. Immunol. Methods 151 (1992), $237-244$.

[40] K.A.A.S. Warnakulasuriya and N.W. Johnson, Expression of p53 mutant nuclear phosphoprotein in oral carcinoma and potentially malignant oral lesions, J. Oral Pathol. Med. 21 (1992), 404-408.

[41] J.T. Woosley and D.R. Dietrich, Prognostic significance of PCNA grade in malignant melanoma, J. Cutan. Pathol. 20 (1993), 498-503.

[42] D. Wynford-Thomas, p53 in tumour pathology: Can we trust immunocytochemistry?, J. Pathol. 166 (1992), 329-330.

[43] U.K. Zätterström, Squamous cell carcinoma of the head and neck. Prognostic factors, cell kinetics and transplantability into nude mice. MedSci. Thesis, University of Lund, Sweden, 1991. 


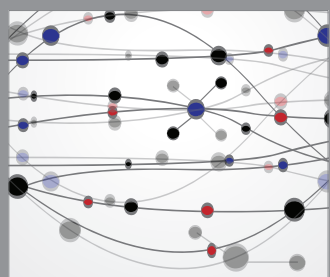

The Scientific World Journal
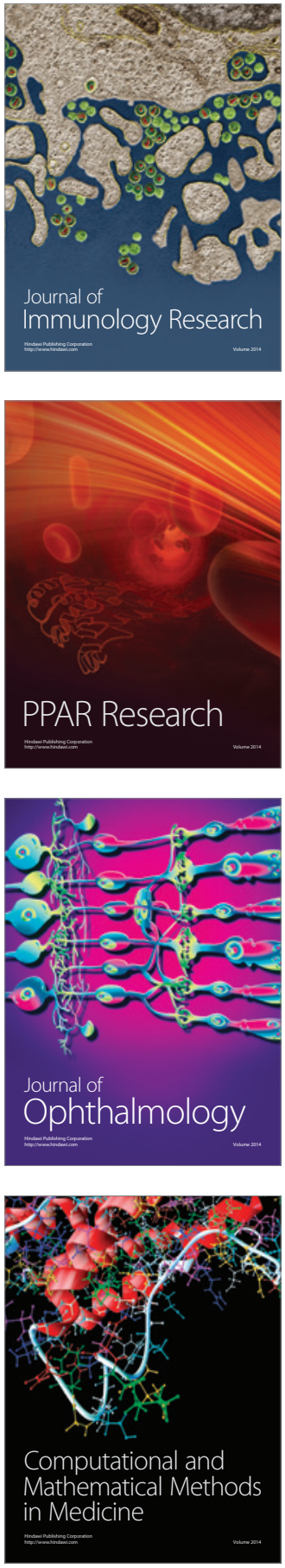

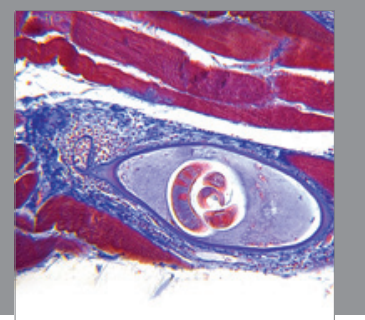

Gastroenterology

Research and Practice
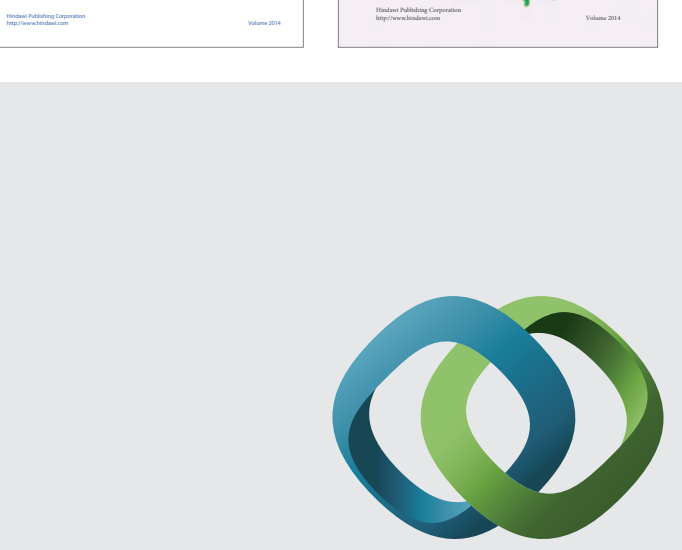

\section{Hindawi}

Submit your manuscripts at

http://www.hindawi.com
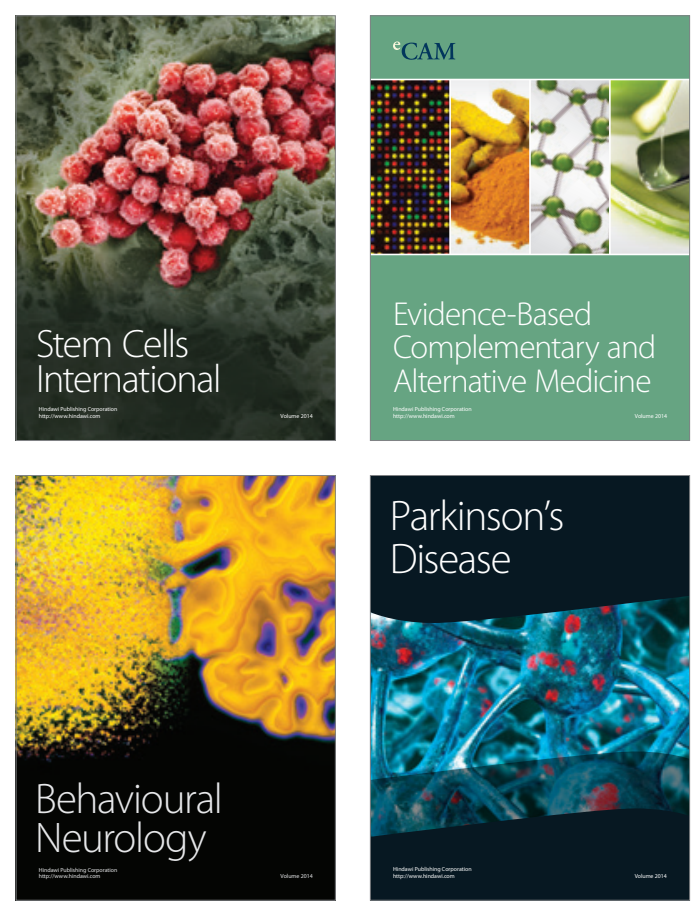

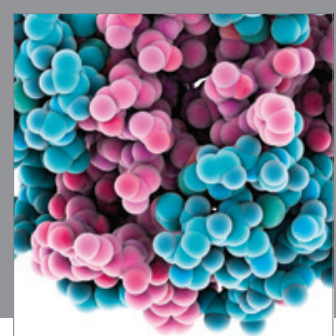

Journal of
Diabetes Research

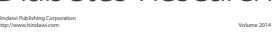

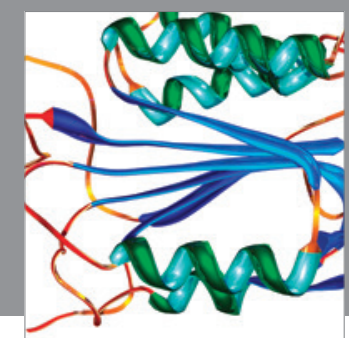

Disease Markers
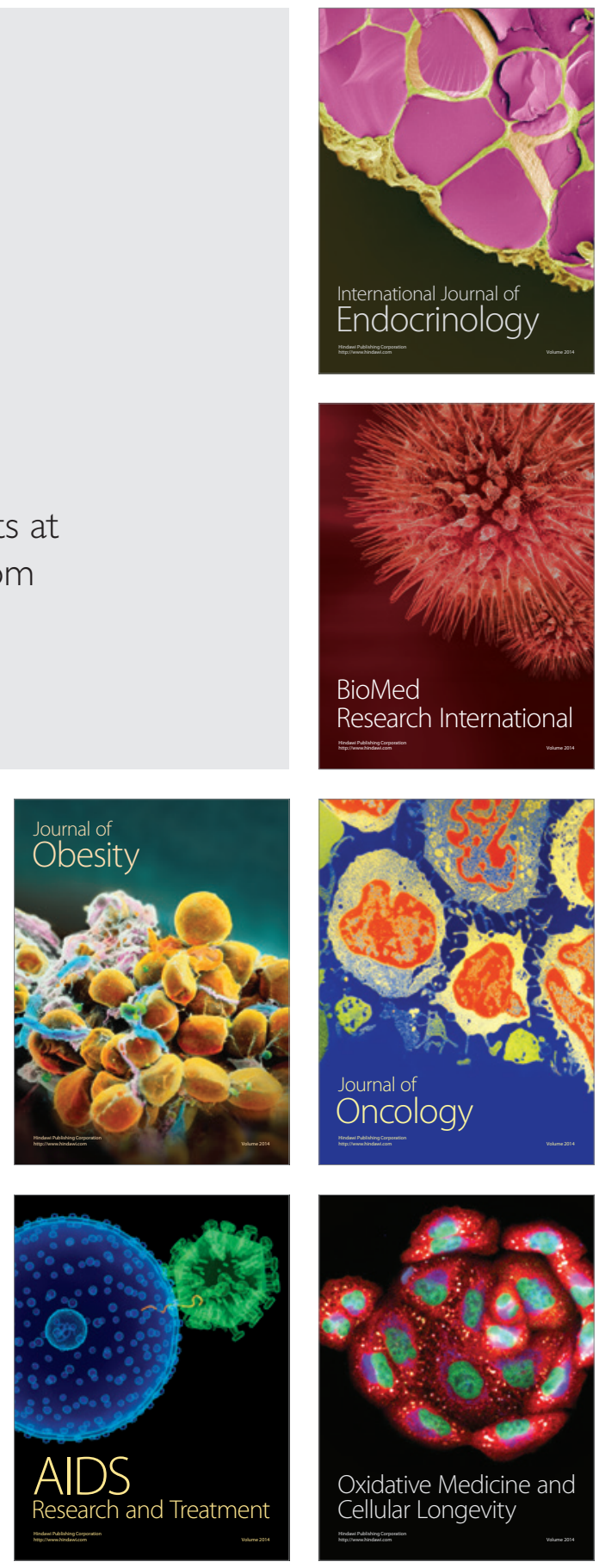